\title{
Planar Hexagonal Antenna with Dual Reconfigurable Notched Bands for Wireless Communication Devices
}

\author{
Houda AYADI ${ }^{1}$, Jan MACHAC ${ }^{2}$, Sabri BELDI ${ }^{1}$, Lassaad LATRACH ${ }^{1}$ \\ ${ }^{1}$ Dept. of Physics, Microwave Electronics Research Laboratory, Faculty of Sciences of Tunis, \\ University of Tunis El Manar, Tunis 2092, Tunisia 2 \\ ${ }^{2}$ Dept. of Electromagnetic Field, Czech Technical University in Prague, \\ Technicka 2, 16627 Prague 6, Czech Republic
}

ayadi_houda@hotmail.fr,machac@fel.cvut.cz, beldi.sabri@gmail.com, latrach.lassaad@gmail.com

Submitted July 17, 2020 / Accepted February 7, 2021

\begin{abstract}
In this paper, a planar hexagonal antenna with dual tunable notched band using varactor diodes is presented. The designed antenna operates in the frequency range of $2 \mathrm{GHz}$ to $8 \mathrm{GHz}$ and is loaded by a complementary split ring resonator (CSRR) to achieve the notch-band characteristics. The CSRR produced two stop-bands at the frequencies $3 \mathrm{GHz}$ and $6.8 \mathrm{GHz}$. In order to obtain the reconfigurability, one varactor diode was used on each ring of the CSRR. The variation of the DC bias of the diodes produced double notched bands yielding a tunable coverage in the $0.6 \mathrm{GHz}$ and $1.6 \mathrm{GHz}$ ranges. The continuous agility and the wide tuning range of the notched bands are the major advantages of this structure. The antenna prototype was manufactured and a good agreement has been achieved between the measured and simulated results. The proposed antenna can be a good candidate for wireless applications that cover the UMTS, the Wi-Fi and the WiMAX bands.
\end{abstract}

\section{Keywords}

Reconfigurable antenna, complementary split ring resonator (CSRR), notched band

\section{Introduction}

During the last two decades, the wideband (WB) technology has drawn great attention to the RF design optimization in terms of complexity, cost, and power consumption. This technology is being intensively studied for many wireless communication systems and applications such as LTE, ISM, GSM, Wi-Fi, WLAN and WiMAX [1].

To overcome the possible interferences and distortions of electromagnetic signals, numerous efforts [2], [3] have been made to design and optimize wideband antennas with specific notched band characteristics. In [4], [5], the authors used the Coplanar Waveguide (CPW) technique to miniaturize wideband (WB) antennas while improving their operation bandwidth. Later, a new compact defected ground structure (DGS) was used for a microstrip line [6] in order to design a compact low pass filter (LPF). In [7], Electromagnetic Band Gap (EBG) was used to minimize the mutual coupling of microstrip antennas. Split ring resonators (SRR) $[8,9,10]$ and complimentary split ring resonators (CSRR) [11], [12] have been a subject of a growing interest in recent years. In fact, they have been used to improve the out-of-band rejection of the antennas as described in [13-16].

Thanks to the growing demand for smart antennas, tuning the notched bands has become a suitable solution. In fact, a reconfigurable frequency structure is appropriate for many wireless applications. Frequency agility is obtained by using several switching technologies such as PIN diodes [17, 18, 19], MEMS (Micro-Electro-Mechanical-Systems) switches [20], [21], and varactor diodes [22].

In this paper, a planar broadband antenna with tunable dual stop-bands has been successfully designed. The main importance of the proposed structure is its high selectivity and its wide tuning range of notched bands.

The first section of this paper is dedicated to introduce the geometry of the broadband antenna and the CSRR structure. The second section is reserved for simulations and measurement results. By introducing a CSRR to the designed antenna, two rejected bands at S-band $(3 \mathrm{GHz})$ and C-band $(6.8 \mathrm{GHz})$ are obtained. Then, the reconfigurability of the double notched bands is obtained by the integration of one varactor diode on each ring of the resonator to decrease the complexity of the bias network.

\section{Antenna Design}

\subsection{Planar Hexagonal Antenna Design}

In this work, the design procedure is performed in several steps. First, the structure of the patch antenna is printed on a $0.76 \mathrm{~mm}$ thick Rogers substrate (RO4350B) 


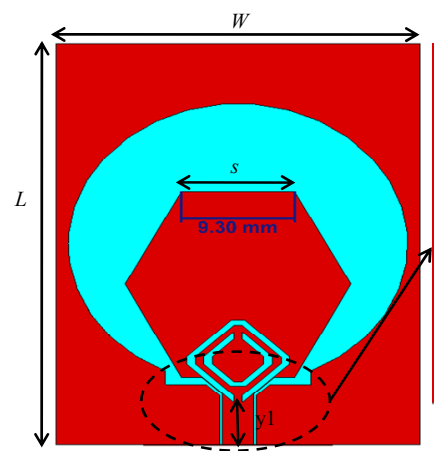

(a)

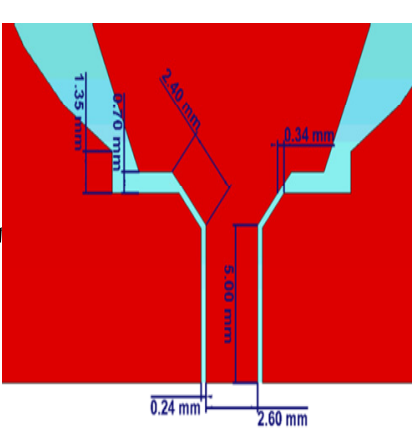

(b)
Fig. 1. (a) Schema of the broadband antenna. (b) Zoomed view of the feed-line of the antenna without CSRR.

with a dielectric constant of 3.66 and a loss tangent of 0.035. The width $W$ and length $L$ of the antenna, calculated from equations cited in [23], are $30 \mathrm{~mm}$ and $40 \mathrm{~mm}$, respectively. A hexagonal patch is placed in a circular aperture with radius of $14 \mathrm{~mm}$ etched on the CPW ground plane. The back side of the substrate is without metalization. The monopole antenna is connected to an SMA connector and is excited by a $50 \Omega$ coplanar waveguide (CPW) feed-line. A complementary split ring resonator (CSRR) is placed in front of the feed-line as shown in Fig. 1(a).

The expression of the resonant frequency of the proposed antenna $f_{\mathrm{r}}$ is as proposed in [24], and inspired from that of the resonant frequency of circular patch antennas for different $\mathrm{TM}_{n m}$ modes such that

$$
f_{\mathrm{r}}=\frac{X_{n m} c}{2 \pi a_{\mathrm{e}} \sqrt{\varepsilon_{\mathrm{r}}}}
$$

where $c$ is the speed of light, $m$ and $n$ are the radial and angular modes, respectively, and $a_{\mathrm{e}}$ is the effective antenna radius such that

$$
\pi a_{\mathrm{e}}^{2}=\frac{3 \sqrt{3}}{2} s^{2} .
$$

Here, $s$ is the hexagon's side length. For the $\mathrm{TM}_{11}$ resonant frequency, $X_{11}$ is found to be 1.841 as given by [24].

\subsection{CSRR Geometry}

The CSRR is an artificially produced structure frequently exploited for antenna design and often used for the design of antennas with rejected bands [25], [26] to improve performances by reducing size and enhancing bandwidth, gain, and radiation patterns.

Figure 2(a) shows the geometry of the proposed CSRR, which is made of two coupled slot rings etched on the upper conductor plane of the substrate and separated by a gap and a split at opposite sides of each ring. The lengths of the outer and inner rings, $L_{1}$ and $L_{2}$, are $5.5 \mathrm{~mm}$ and $3.5 \mathrm{~mm}$, respectively. The common width for the two rings is $w=0.5 \mathrm{~mm}$. The space between the rings $g$ is $0.5 \mathrm{~mm}$ and the opening gap $s$ is $0.7 \mathrm{~mm}$. The simulation of this structure is carried out using the CST Microwave Studio

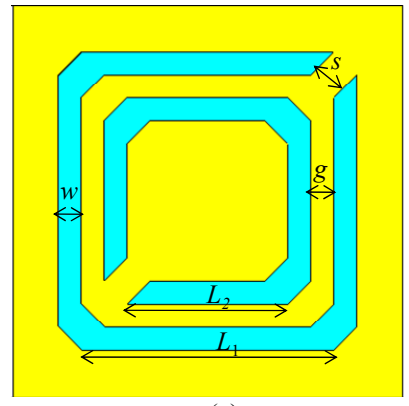

(a)

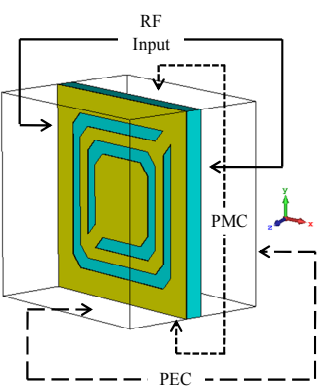

(b)
Fig. 2. (a) Geometry of the proposed CSRR. (b) Simulation setup.

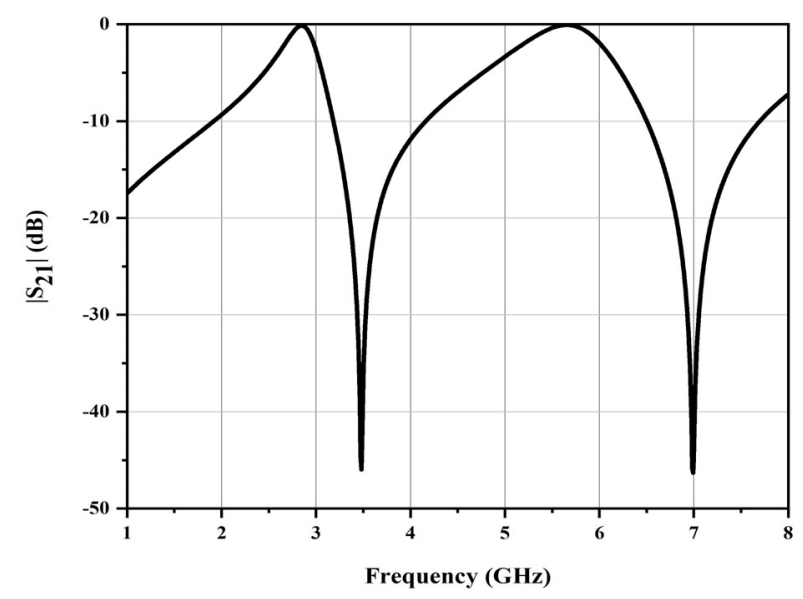

Fig. 3. Simulated transmission coefficient magnitude of the resonator.

software. To simulate and acquire desired results, boundary conditions and excitation sources need to be identified. Figure 2(b) shows the unit cell simulation setup; two Perfect Electric Conductor (PEC) walls are set as boundaries on the front and back sides of the waveguide along the $\mathrm{z}$ axis and two Perfect Magnetic Conductor (PMC) walls are placed on the top and bottom sides along the y-axis. The remaining two sides are used for signal excitation along the $\mathrm{x}$-axis.

The simulated transmission coefficient magnitude $\left|S_{21}\right|$ of the proposed CSRR is illustrated in Fig. 3. As it can be observed, two resonant frequencies appeared at $3.5 \mathrm{GHz}$ and $7 \mathrm{GHz}$.

\section{Simulations Results}

In this work, the simulation results of the designed antenna were investigated by exploiting the CST Microwave Studio software.

\subsection{Simulation Results of the Designed An- tenna Structure with and without CSRR}

Figure 4 presents the reflection coefficient magnitudes of the designed antenna with and without the CSRR resonator. It is observed that the designed antenna without 
CSRR can produce wideband impedance matching from 2 to $8 \mathrm{GHz}$ with a reflection coefficient magnitude $\left|S_{11}\right| \leq$ $-10 \mathrm{~dB}$. Whereas the insertion of the CSRR on the designed antenna structure provides the appearance of two notched bands, each ring of the resonator controls a single notched band independently. The first rejected frequency band is spread around $3 \mathrm{GHz}$ and is controlled by the external ring while the second one is spread around $6.8 \mathrm{GHz}$ and is controlled by the internal ring. This makes the resonator suitable for monitoring two notched frequency bands simultaneously or independently.

A parametric study of different positions of the CSRR on the antenna along the y-axis was performed and it proved that the optimal position is obtained when the CSRR is near the feed-line with $y_{1}=4.7 \mathrm{~mm}$, where the unit cell illustrates the highest rejection band $\left|S_{11}\right| \geq-2$ and $-4 \mathrm{~dB}$, respectively. Moreover, the integration of the CSRR in the structure reduces around $20 \%$ of the antenna size since its resonant frequency decreased from $5.8 \mathrm{GHz}$ to $4.8 \mathrm{GHz}$.

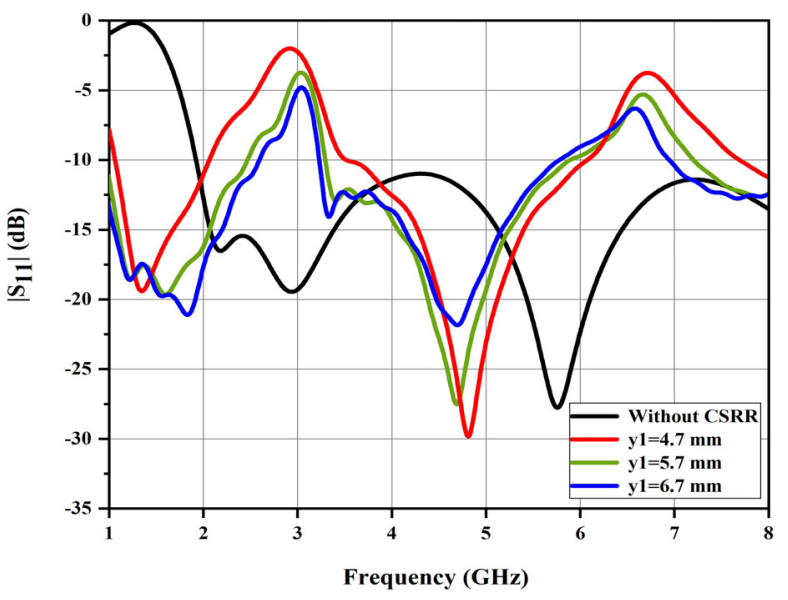

Fig. 4. Reflection coefficient magnitudes of the designed antenna with and without CSRR for different positions of $y_{1}$.

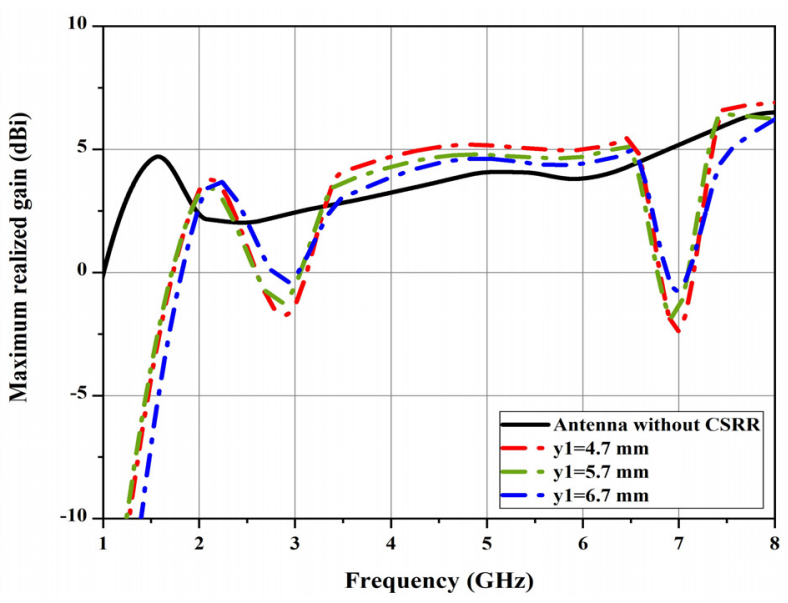

Fig. 5. Maximum realized gain of the designed antenna with and without CSRR for different positions of $y_{1}$.

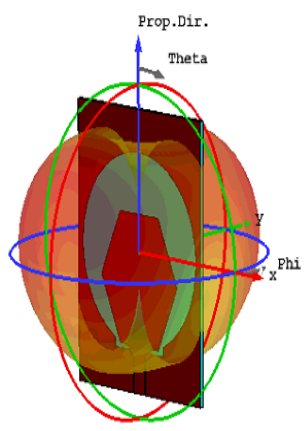

(a)

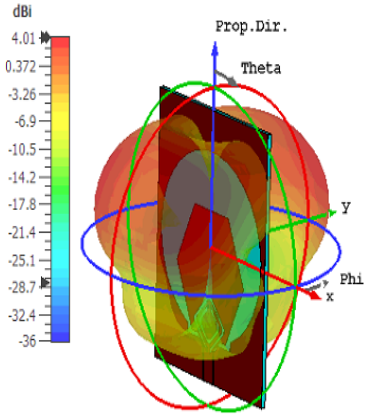

(b)

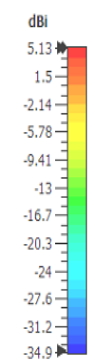

Fig. 6. Three-dimensional radiation pattern of the designed antenna at $5 \mathrm{GHz}$. (a) Calculated gain without CSRR. (b) Calculated gain with CSRR at the position $y_{1}=4.7 \mathrm{~mm}$.

The obtained maximum gain of the antenna over the frequency range of [2 to $8 \mathrm{GHz}$ ] with and without the CSRR is presented in Fig. 5. It should be noted that the increase of frequency leads to the increase of the antenna gain without the CSRR. By adding the CSRR to the antenna, the gain is improved except for the two rejection zones where the gain decreased to $-2 \mathrm{dBi}$.

The three-dimensional radiation patterns of the designed antenna with and without the CSRR at the frequency of $5 \mathrm{GHz}$ are presented in Fig. 6. It can be observed that the realized gain increased from $4 \mathrm{dBi}$ without CSRR to $5.13 \mathrm{dBi}$ with CSRR. The obtained results show also that, the antenna has an omnidirectional radiation pattern in the $(\mathrm{x}, \mathrm{y})$ plane. Therefore, it can be concluded that the insertion of the CSRR in the antenna structure improves the behavior of the antenna without disturbing its radiation features.

To manifest the performance of the designed antenna, the total efficiency with and without the CSRR is simulated and drawn in Fig. 7. For both cases, the antenna has a good radiation efficiency of up to $90 \%$, apart from the notched frequency bands where the efficiency decreased to $20 \%$.

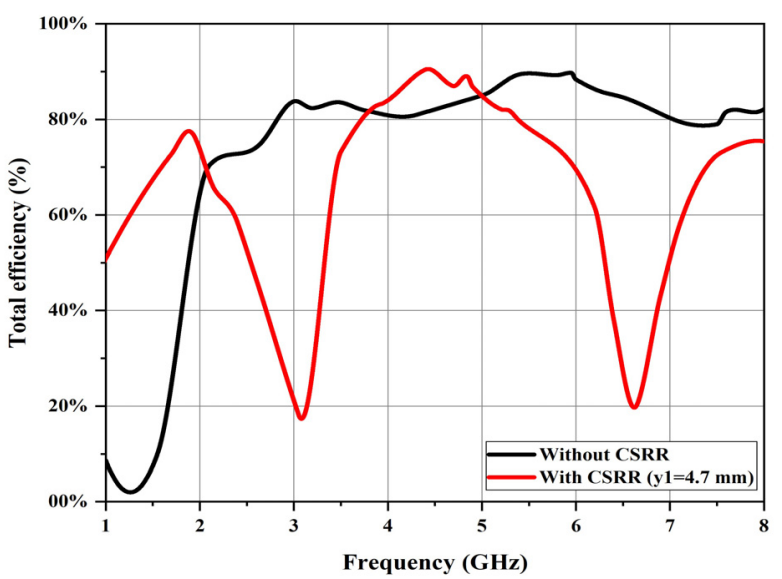

Fig. 7. Total efficiency of the antenna with and without CSRR over frequencies. 


\subsection{Simulation of the Designed Antenna Structure using Varactor Diodes}

Figure 8 shows the final designed antenna layout. The reconfigurability is obtained by loading the SKYWORKS varactor diode (SMV1430-040LF) on each ring of the CSRR [27].

The equivalent circuit of the diode is shown in Fig. 9. The capacitance of the used diodes can be controlled from 0.3 to $1.29 \mathrm{pF}$ by varying the reverse bias voltage. In addition, two metalized vias are used to connect the diodes with two insulated square patches laid on the back side of the structure. These patches with the appropriate dimension $\left(5 \times 5 \times 0.035 \mathrm{~mm}^{3}\right)$ lead to the highest rejection band $\left(\left|S_{11}\right| \geq-3 \mathrm{~dB}\right)$. Then, the DC voltage is connected via a CC45T47K240G5 inductor to isolate the RF signal and a $20 \mathrm{k} \Omega$ resistor to protect the diodes [21]. During the simulation, the varactor is treated as a lumped element by considering a resistance $R$ in series with a capacitance $C$. The values are extracted from the datasheet of the component.

To load the diodes in the appropriate positions, the surface current distribution in the antenna is studied as shown in Fig. 10. Indeed, at the rejected frequency $3 \mathrm{GHz}$, the current is concentrated in the outer ring, while at $6.8 \mathrm{GHz}$ (the second reject frequency), the current is concentrated in the inner ring. However, in both cases the surface current distribution is concentrated near slots.

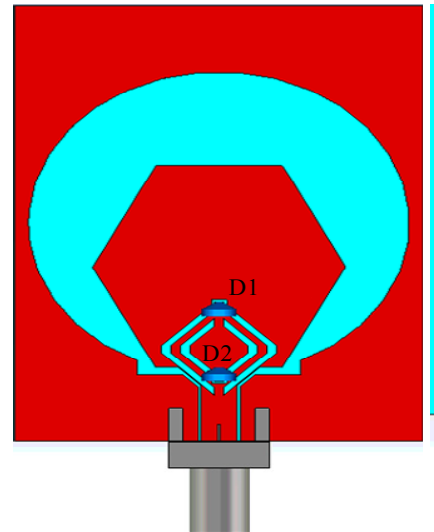

(a)

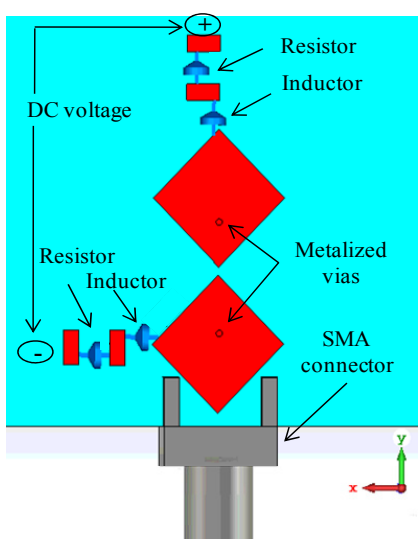

(b)
Fig. 8. (a) Top view of the designed antenna loaded with CSRR and varactor diodes. (b) Zoomed bottom view of the polarization circuit of the diodes.

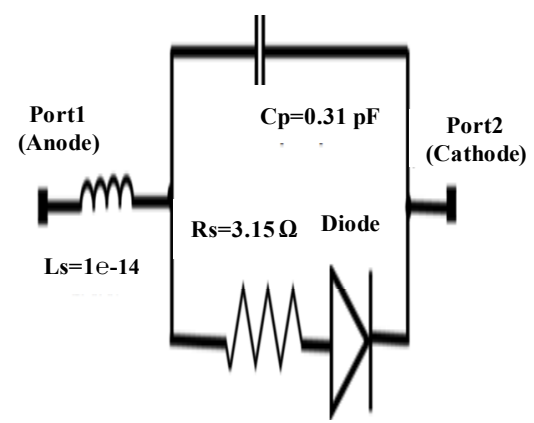

Fig. 9. Equivalent model of the SMV1430-040LF varactor diode.

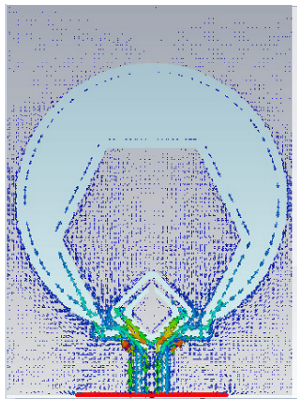

(a)

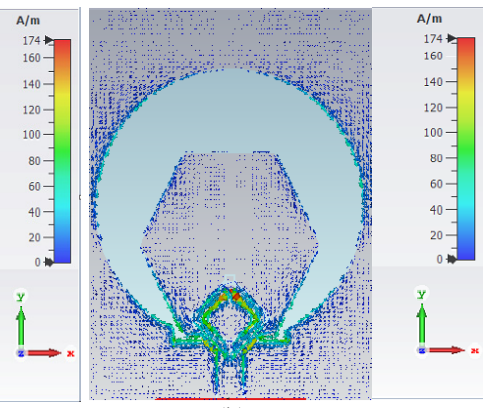

(b)
Fig. 10. Flow of surface current of the antenna in the presence of CSRR at: (a) $3 \mathrm{GHz}$, (b) $6.8 \mathrm{GHz}$.

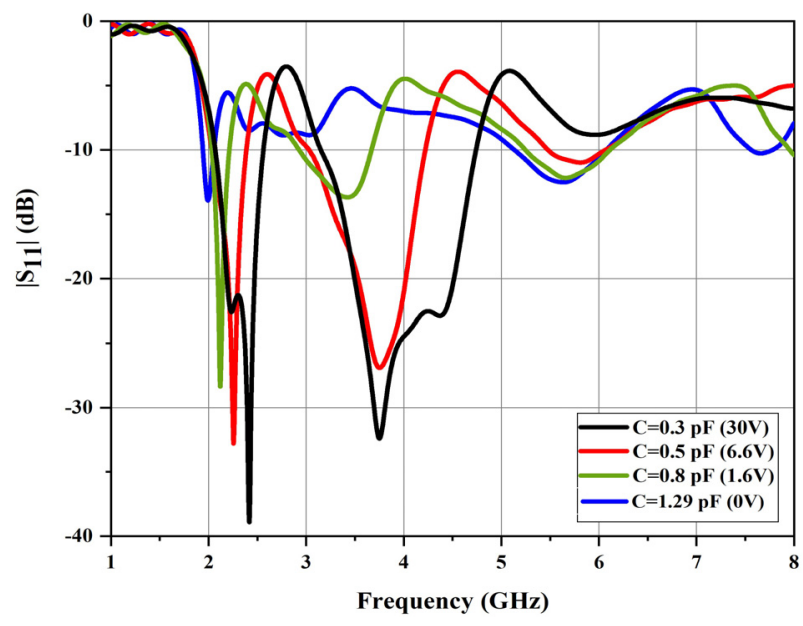

Fig. 11. Simulated reflection coefficient magnitudes for some values of $\mathrm{C}$.

The proposed antenna has been simulated for equal capacitance values $C=C_{1}=C_{2}$. Figure 11 shows the magnitude of the obtained reflection coefficient $\left|S_{11}\right|$ for different values of $C$ in $[0.3,0.5,0.8$, and 1.29] pF. As shown in the figure, increasing $C$ causes the notched bands to shift towards lower frequencies. The first band shifted from 2.8 to $2.2 \mathrm{GHz}$, leading to a tuning range of $0.6 \mathrm{GHz}$, while the second band is shifted from 5 to $3.4 \mathrm{GHz}$ leading to a tuning range of $1.6 \mathrm{GHz}$. This makes the antenna a good candidate for multimode and multi standard applications such as UMTS, Wi-Fi and WiMAX.

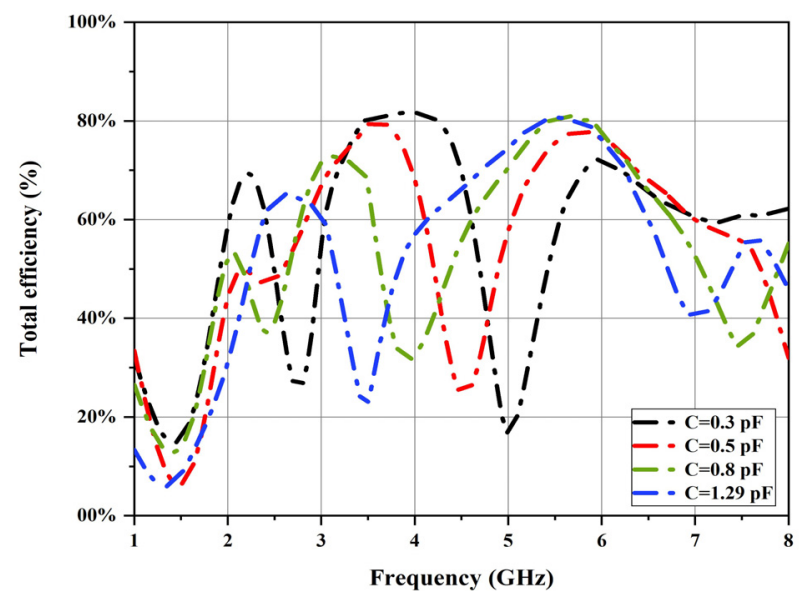

Fig. 12. Total efficiency of the antenna for different values of $C$ over frequencies. 
Figure 12 illustrates the total efficiency of the antenna for several values of $C$. An efficiency as high as $80 \%$ has been observed in the pass-band frequencies, while a low efficiency, not exceeding $40 \%$, has been observed at the rejection zones that change position with the value of $C$.

Since each diode controls one rejection zone, varying $C_{1}$ and $C_{2}$ separately allows to control the two rejection zones separately and hence offers more flexibility and adds more reconfigurability to the proposed design. Figure 13(a) presents the reflection coefficient magnitudes of the antenna for $\left(C_{1}, C_{2}\right)=(0.3,0.3) \mathrm{pF}, \quad(0.3,0.5) \mathrm{pF}$, $(0.3,0.8) \mathrm{pF}$ and $(0.3,1.29) \mathrm{pF}$. The figure clearly shows the shifting of the second rejection band while the first band remained in place. Similarly, Figure 13(b) presents the same reflection coefficient magnitudes for $\left(C_{1}, C_{2}\right)=$ $(0.3,0.5) \mathrm{pF},(0.5,0.5) \mathrm{pF},(0.8,0.5) \mathrm{pF}$ and $(1.29,0.5) \mathrm{pF}$. Once again, the figure reveals the shifting of the first band while the second band remained unchanged. The shifting values for the first and the second rejection bands are $1 \mathrm{GHz}$ and $0.5 \mathrm{GHz}$, respectively.

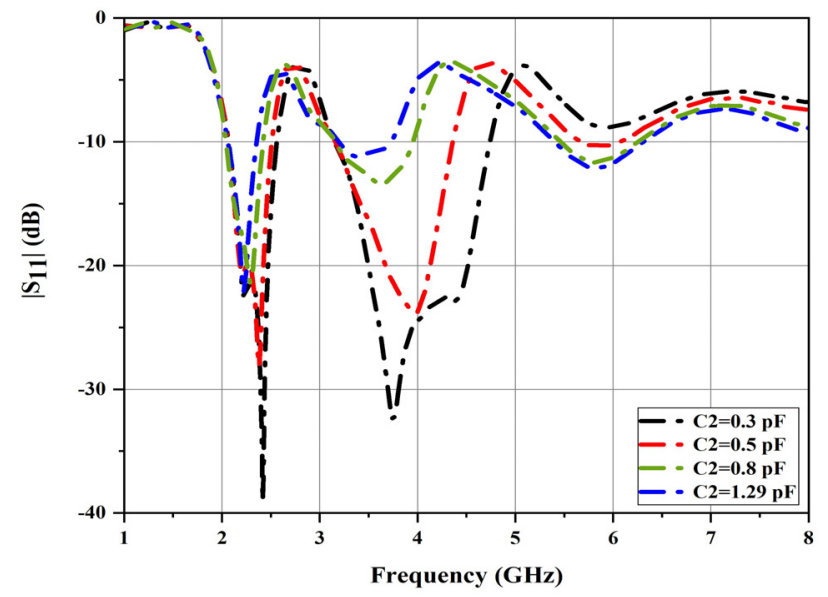

(a)

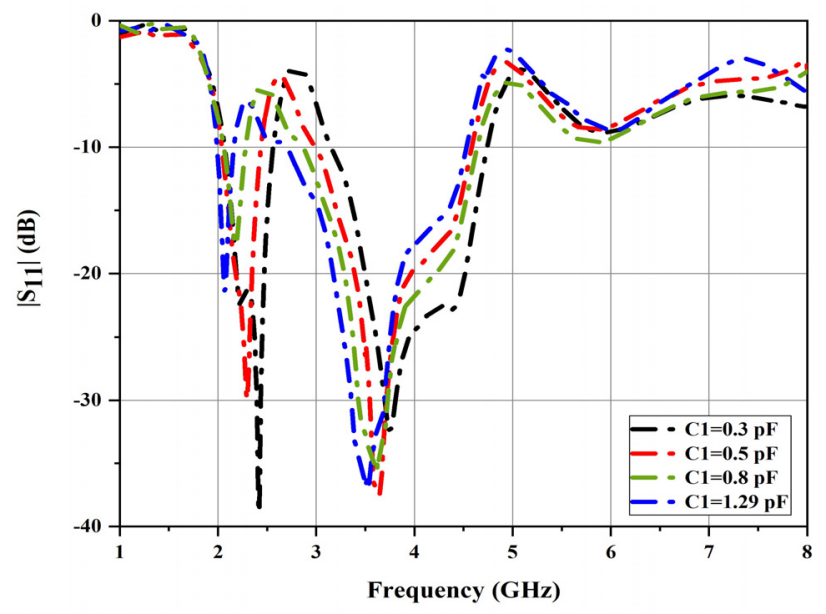

(b)

Fig. 13. Simulated reflection coefficient magnitudes for $C_{1}$ different from $C_{2}$ : (a) $C_{1}$ fixed at $0.3 \mathrm{pF}$ and $C_{2}$ variable, (b) $C_{2}$ fixed at $0.5 \mathrm{pF}$ and $C_{1}$ variable.

\section{Measurements Results}

The reconfigurable wideband antenna was manufactured as shown in Fig. 14. Two varactor diodes were soldered on the realized antenna. To measure the magnitude of the reflection coefficient over the frequency range from $2 \mathrm{GHz}$ to $8 \mathrm{GHz}$, a vector network analyzer was used. The gain and the radiation pattern measurements were performed in an anechoic chamber. For experimental purposes, the capacitances of the varactor diodes are considered equal: $C=C_{1}=C_{2}$.

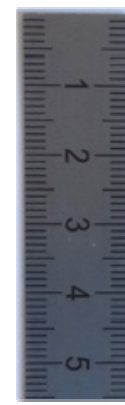

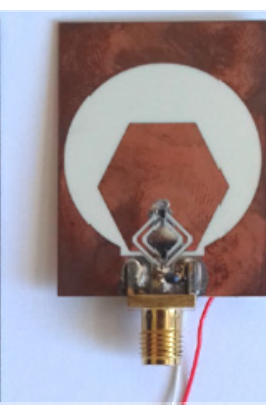

(a)
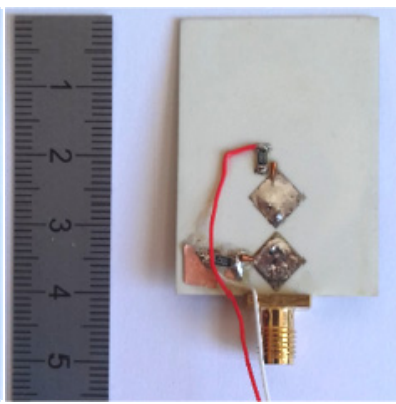

(b)
Fig. 14. Photographs of the realized prototype: (a) Top view of the reconfigurable band reject antenna. (b) Bottom view of the reconfigurable band reject antenna.

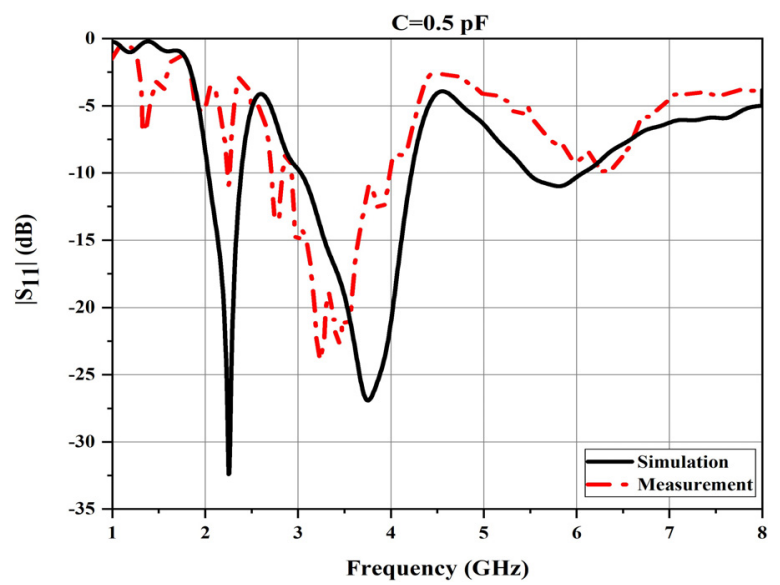

(a)

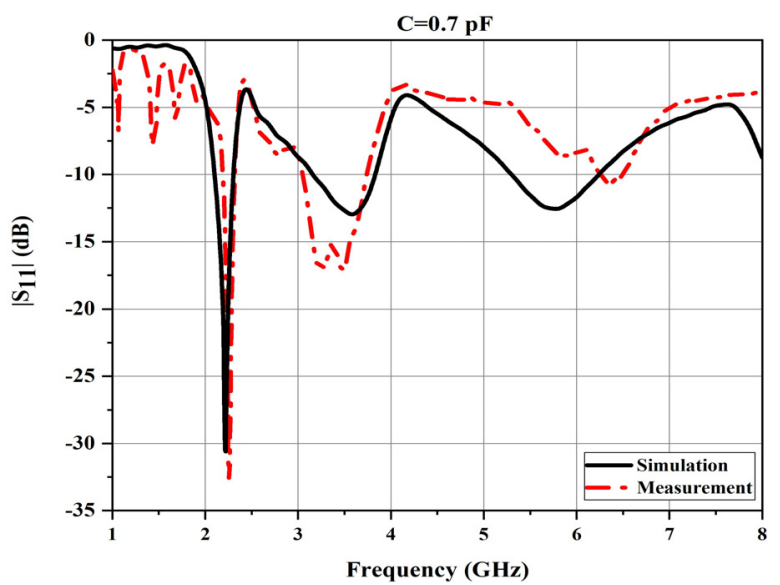

(b) 


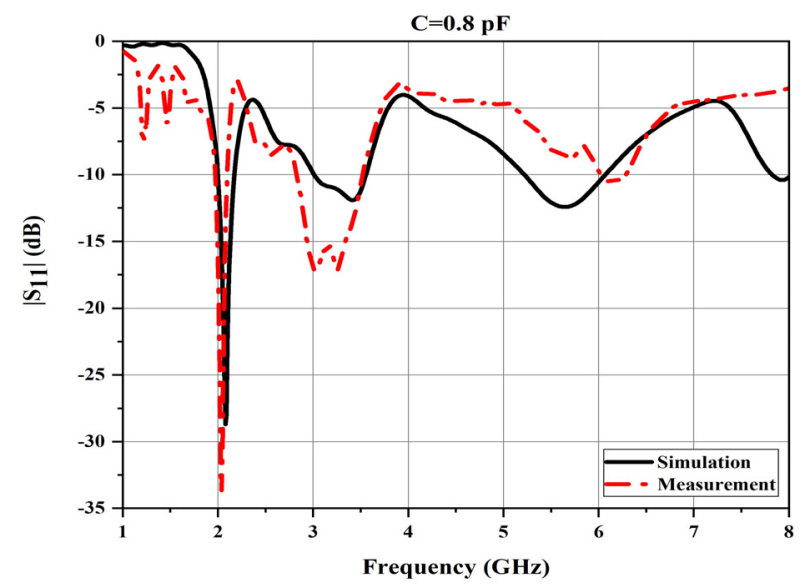

(c)

Fig. 15. Simulated and measured reflection coefficient magnitudes with two varactor diodes for different values of capacitance $C$ : (a) $0.5 \mathrm{pF}$, (b) $0.7 \mathrm{pF}$ and (c) $0.8 \mathrm{pF}$.

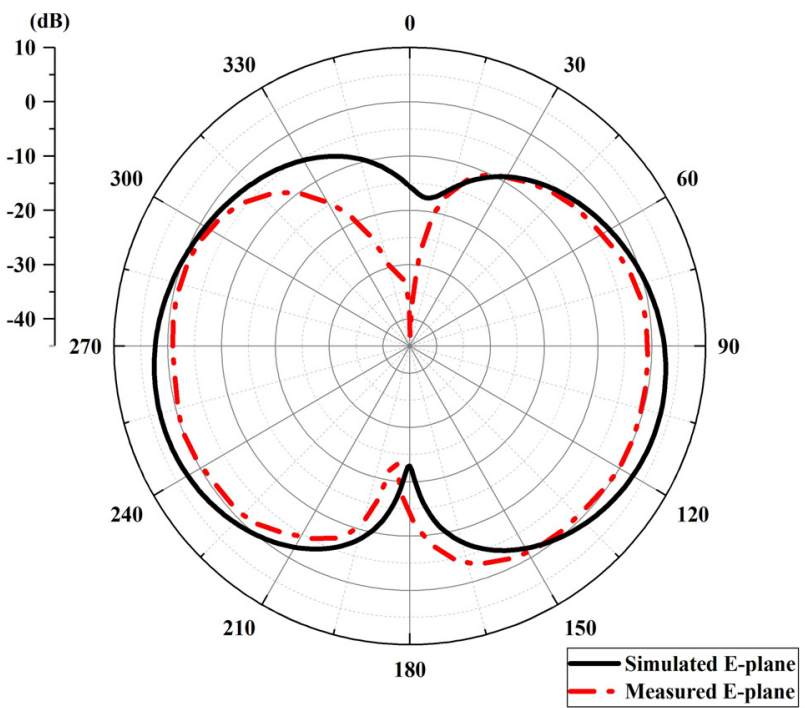

(a)
Figure 15 presents the simulated and measured reflection coefficient magnitudes of the designed antenna. The figure reveals a small discrepancy between the measured and simulated results that can be due to the approximate boundary conditions used in simulation as well as the accuracy of the diode's model, in addition to the material defects. Based on the capacitance values, the antenna can cover UMTS, Wi-Fi, and WiMAX bands depending on the desired application.

Figures 16 and 17 show the simulated and measured radiation patterns of the proposed broadband antenna in the E-plane (yoz) at some selected frequencies for $C=0.8 \mathrm{pF}$ and $C=0.5 \mathrm{pF}$. A stable radiation pattern is obtained and is well maintained over the whole operating frequency bandwidth. As a conclusion, the reconfigurable CSRR removes the unwanted bands without affecting the antenna radiation performance.

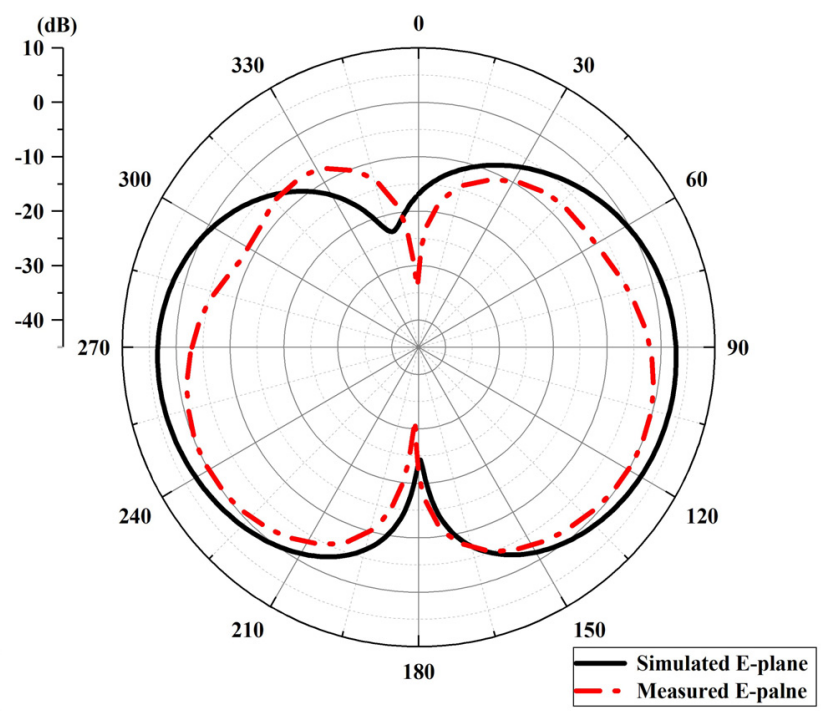

(b)

Fig. 16. Measured radiation patterns for the reconfigurable antenna for $C=0.8 \mathrm{pF}(1.6 \mathrm{~V})$ of the diodes $\mathrm{D} 1$ and $\mathrm{D} 2$ at frequencies: (a) $2 \mathrm{GHz}$, (b) $3.3 \mathrm{GHz}$

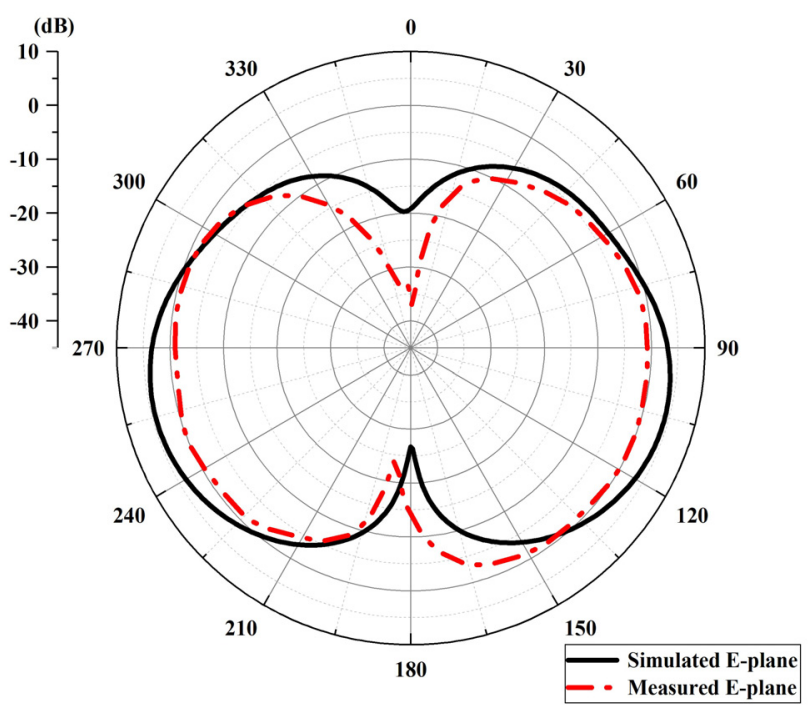

(a)

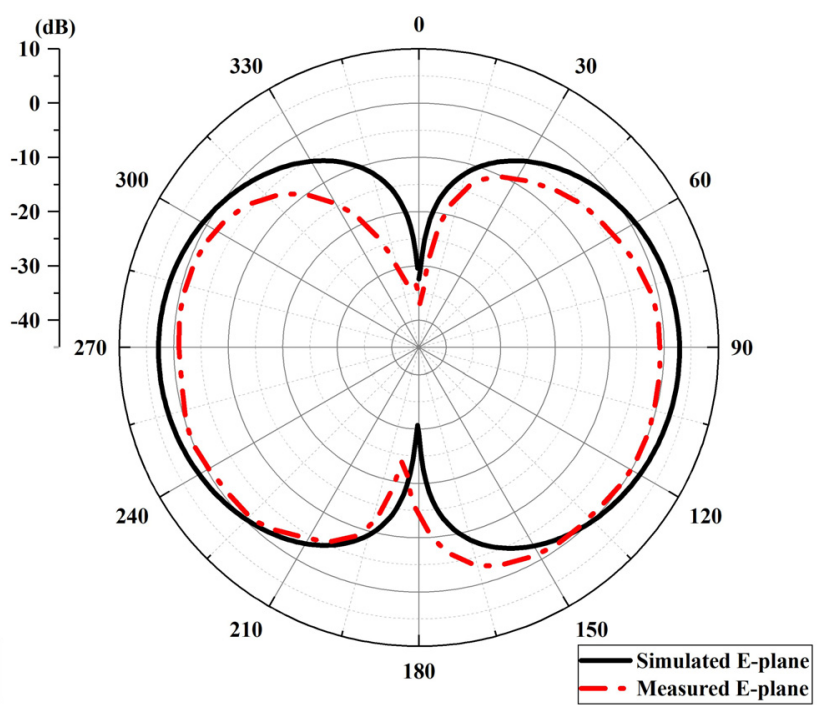

(b)

Fig. 17. Measured radiation patterns for the reconfigurable antenna for $C=0.5 \mathrm{pF}(6.6 \mathrm{~V})$ of the diodes $\mathrm{D} 1 \mathrm{and} \mathrm{D} 2$ at frequencies: (a) $2.2 \mathrm{GHz}$, (b) $3.6 \mathrm{GHz}$ 


\begin{tabular}{|c|c|c|c|c|c|}
\hline \multirow[b]{2}{*}{$\begin{array}{c}\text { Capacitance value } \\
(\mathrm{pF})\end{array}$} & \multirow[b]{2}{*}{$\begin{array}{l}\text { Bias Voltage } \\
\text { (V) }\end{array}$} & \multicolumn{2}{|c|}{ Simulations } & \multicolumn{2}{|c|}{ Measurements } \\
\hline & & $\begin{array}{c}\text { First rejected freq. } \\
\text { (GHz) }\end{array}$ & $\begin{array}{l}\text { Second rejected freq. } \\
\text { (GHz) }\end{array}$ & $\begin{array}{c}\text { First rejected freq. } \\
\text { (GHz) }\end{array}$ & $\begin{array}{l}\text { Second rejected freq. } \\
\text { (GHz) }\end{array}$ \\
\hline$C=0.3$ & 30 & 2.8 & 5 & 2.63 & 5.15 \\
\hline$C=0.4$ & 17 & 2.62 & 4.73 & 2.50 & 4.70 \\
\hline$C=0.5$ & 6.6 & 2.53 & 4.46 & 2.43 & 4.50 \\
\hline$C=0.7$ & 2.5 & 2.37 & 4.10 & 2.30 & 3.90 \\
\hline$C=0.8$ & 1.6 & 2.35 & 4.08 & 2.27 & 3.85 \\
\hline$C=1.29$ & 0 & 2.2 & 3.4 & 2 & 3.55 \\
\hline
\end{tabular}

Tab. 1. Rejected frequencies of the designed antenna for different capacitance values.

\begin{tabular}{|c|c|c|c|}
\hline References & Number of diodes & Maximum tuning range & Maximum gain \\
\hline$[3]$ & 2 varactor diodes & $0.8 \mathrm{GHz}$ & - \\
\hline$[28]$ & 2 varactor diodes & $0.8 \mathrm{GHz}$ & $6.5(\mathrm{dBi})$ \\
\hline$[29]$ & 3 PIN diodes & $0.6 \mathrm{GHz}$ & $7(\mathrm{dBi})$ \\
\hline$[30]$ & 3 varactor diodes & $0.32 \mathrm{GHz}$ & $5.8(\mathrm{dBi})$ \\
\hline Proposed antenna & 2 varactor diodes & $1.6 \mathrm{GHz}$ & $6.8(\mathrm{dBi})$ \\
\hline
\end{tabular}

Tab. 2. A comparison of various tunable and switchable band-notched WB antennas.

From Tab. 1, the capacitance value and the applied voltage are inversely proportional. In addition, varying the capacitance values of the two diodes attached to each ring of CSRR from 0.3 to $1.29 \mathrm{pF}$ leads to a variation of the notched frequency band from 2.63 to $2 \mathrm{GHz}$ for the first notched band and from 5.15 to $3.55 \mathrm{GHz}$ for the second notched band, respectively. The tuning range of the first rejected band is around $0.6 \mathrm{GHz}$ while the second is around $1.6 \mathrm{GHz}$. These effects make the antenna advantageous in terms of dual wide tuning ranges. The simulated and measured results show a good agreement.

Table 2 presents a comparative study of performances of the designed antenna with other existing reconfigurable notched antennas [3], [28, 29, 30]. It is observed that the designed reconfigurable notched antenna presents an important improvement in terms of radiation characteristics and simplicity of design. Furthermore, a wide tuning range of $1.6 \mathrm{GHz}$ is achieved.

\section{Conclusion}

In this work, a wideband antenna with double tunable notched bands is designed. The integration of the CSRR resonator in the antenna structure provides two rejected bands at $3 \mathrm{GHz}$ and $6.8 \mathrm{GHz}$. The tuning of the rejected bands is obtained using two varactor diodes in the antenna structure. The tuning ranges of the first and second notched bands are around $0.6 \mathrm{GHz}$ and $1.6 \mathrm{GHz}$, respectively.
These wide tuning ranges are obtained by varying the capacitance values of the varactor diodes by sweeping their reverse bias voltage from 0 to $30 \mathrm{~V}$. The developed wideband planar antenna with reconfigurable frequency notched bands, tuning range, moderate gain, and stable radiation patterns may be a potential structure for modern wireless communication systems.

\section{Acknowledgments}

The experimental work and fabrication have been supported by the Grant Agency of the Czech Republic under project No. 20-02046S.

\section{References}

[1] LI, T., ZHAI, H., WANG, X., et al. Frequency-reconfigurable bow-tie antenna for Bluetooth, WiMAX, and WLAN applications. IEEE Antennas and Wireless Propagation Letters, 2014, vol. 14, p. 171-174. DOI: 10.1109/LAWP.2014.2359199

[2] KUMAR, G., KUMAR, R. A survey on planar ultra-wideband antennas with band notch characteristics: Principle, design, and applications. International Journal of Electronics and Communications (AEÜ), 2019, vol. 109, p. 76-98. DOI: 10.1016/j.aeue.2019.07.004

[3] BEN TRAD, I., FLOCH, J. M., RMILI, H., et al. Planar elliptic broadband antenna with wide range reconfigurable narrow notched bands for multi-standard wireless communication devices. 
Progress In Electromagnetics Research, 2014, vol. 145, p. 69-80. DOI: 10.2528/PIER13122701

[4] RAHMAN, M. U. CPW fed miniaturized UWB tri-notch antenna with bandwidth enhancement. Advances in Electrical Engineering, 2016, p. 1-8. DOI: $10.1155 / 2016 / 7279056$

[5] HU, S., WU, Y., ZHANG, Y., et al. Design of a CPW-fed ultra wide band antenna. Open Journal of Antennas and Propagation, 2013, vol. 1, no. 2, p. 18-22. DOI: 10.4236/ojapr.2013.12005

[6] MANDAL, M. K., SANYAL, S. A novel defected ground structure for planar circuits. IEEE Microwave and Wireless Components Letters, 2006, vol. 16, no. 2, p. 93-95. DOI: 10.1109/LMWC.2005.863192

[7] YANG, F., RAHMAT-SAMII, Y. Microstrip antennas integrated with electromagnetic band-gap (EBG) structures: A low mutual coupling design for array applications. IEEE Transactions on Antennas and Propagation, 2003, vol. 51, no. 10, p. 2936-2946. DOI: 10.1109/TAP.2003.817983

[8] FAlCONE, F., LOPETEGI, T., LASO, M. A. G., et al. Babinet principle applied to the design of metasurfaces and metamaterials. Physical Review Letters, 2004, vol. 93, no. 19, p. 1-4. DOI: 10.1103/PhysRevLett.93.197401

[9] BARBUTO, M., BILOTTI, F., TOSCANO, A. Design of a multifunctional SRR-loaded printed monopole antenna. International Journal of RF and Microwave Computer-Aided Engineering, 2012, vol. 22, no. 4, p. 552-557. DOI: $10.1002 /$ mmce. 20645

[10] BARBUTO, M., TROTTA, F., BILOTTI, F., et al. Horn antennas with integrated notch filters. IEEE Transactions on Antennas and Propagation, 2014, vol. 63, no. 2, p. 781-785. DOI: 10.1109/TAP.2014.2378269

[11] FAlCONE, F., LOPETEGI, T., BAENA, J. D., et al. Effective negative- $\varepsilon$ stopband microstrip lines based on complementary split ring resonators. IEEE Microwave and Wireless Components Letters, 2004, vol. 14, no. 6, p. 280-282. DOI: 10.1109/LMWC.2004.828029

[12] YAN, B., JIANG, D., XU, R., et al. A UWB band-pass antenna with triple-notched band using common direction rectangular complementary split-ring resonators. International Journal of Antennas and Propagation, 2013, vol. 2013, p. 1-6. DOI: $10.1155 / 2013 / 934802$

[13] MANSHOURI, N., YAZGAN, A., MALEKI, M. A microstrip-fed ultra-wideband antenna with dual band-notch characteristics. In The $39^{\text {th }}$ International Conference on Telecommunications and Signal Processing (TSP). Vienna (Austria), 2016, p. 231-234. DOI: 10.1109/TSP.2016.7760867

[14] SARKAR, D., SRIVASTAVA. K. V., SAURAV. K. A compact microstrip-fed triple band-notched UWB monopole antenna. IEEE Antennas and Wireless Propagation Letters, 2014, vol. 13, p. 396-399. DOI: 10.1109/LAWP.2014.2306812

[15] DHANESH, V. K., ANURENJAN, P. R. Trapezoidal antenna with triple band-notched for UWB applications. In IEEE Annual India Conference (INDICON). Bangalore (India), 2016, p. 1-5. DOI: 10.1109/INDICON.2016.7838941

[16] KAHNG, S., SHIN, E. C., JANG, G. H., et al. A UWB antenna combined with the CRLH metamaterial UWB bandpass filter having the bandstop at the $5 \mathrm{GHz}$-band WLAN. In IEEE Antennas and Propagation Society International Symposium. North Charleston (SC, USA), 2009, p. 1-4. DOI: 10.1109/APS.2009.5172114

[17] FAKHARIAN, M. M., REZAEI, P., OROUJI, A. A. A multireconfigurable CLL-loaded planar monopole antenna. Radioengineering, 2020, vol. 29, no. 2 , p. 313-320. DOI: $10.13164 /$ re. 2020.0313

[18] QUDDUS, A., SALEEM, R., SHAFIQUE, M. F., et al. Compact electronically reconfigurable WiMAX band-notched ultra- wideband MIMO antenna. Radioengineering, 2018, vol. 27, no. 4, p. 998-1005. DOI: 10.13164/re.2018.0998

[19] ALHEGAZI, A., ZAKARIA, Z., SHAIRI, N. A., et al. A novel reconfigurable UWB filtering-antenna with dual sharp band notches using double split ring resonators. Progress In Electromagnetics Research, 2017, vol. 79, p. 185-198. DOI: 10.2528/PIERC17092302

[20] CHAABANE, G., MADRANGEAS, V., CHATRAS, M., et al. High linearity 3-bit frequency tunable planar inverted F-antenna for RF applications. IEEE Antennas and Wireless Propagation Letters, 2017, vol. 16, p. 983-986. DOI: 10.1109/LAWP.2016.2615874

[21] ANGUERA, J., ANDÚJAR, A., LEIVA, J. L., et al. Multiband antenna operation with a non-resonant element using a reconfigurable matching network. In The 12th European Conference on Antennas and Propagation (EUCAP). London (UK), 2018, p. 1-4. DOI: $10.1049 /$ cp.2018.1199

[22] AGHDAM, S. A. A novel UWB monopole antenna with tunable notched behavior using varactor diode. IEEE Antennas and Wireless Propagation Letters, 2014, vol. 13, p. 1243-1246. DOI: 10.1109/LAWP.2014.2332449

[23] BALANIS, C. A. Antenna Theory: Analysis and Design. $2^{\text {nd }}$ ed. USA: John Wiley \& Sons, 1997. ISBN: 0471592684, 9780471592686

[24] DINESH, V., MURUGESAN, G. A. CPW-fed hexagonal antenna with fractal elements for UWB applications. Applied Mathematics \& Information Sciences, An International Journal, 2019, vol. 13, no. 1, p. 73-79. DOI: $10.18576 /$ amis/130110

[25] KIM, D. O., JO, N. I., JANGAND, H. A., et al. Design of the ultrawideband antenna with a quadruple-band rejection characteristics using a combination of the complementary split ring resonators. Progress In Electromagnetics Research, 2011, vol. 112, p. 93-107. DOI: 10.2528/PIER10111607

[26] KALYAN, R., REDDY, K. T. V., PADMA PRIYA, K. Compact CSRR etched UWB microstrip antenna with quadruple band refusal characteristics for short distance wireless communication applications. Progress In Electromagnetics Research, 2019, vol. 82, p. 139-146. DOI: 10.2528/PIERL19010601

[27] SKYWORKS. SMV1405 to SMV1430 Series: Plastic Packaged Abrupt Junction Tuning Varactors. 10 pages. [Online] Cited 201601-25. Available at :

https://www.mouser.fr/datasheet/2/472/SMV1405_1430_Series_2 00068V-1079581.pdf

[28] TANG, M. C., WANG, H., DENG, T., et al. Compact planar ultrawideband antennas with continuously tunable independent band-notched filter. IEEE Transactions on Antennas and Propagation, 2016, vol. 64, no. 8, p. 3292-3301. DOI: 10.1109/TAP.2016.2570254

[29] ORAIZI, H., SHAHMIRZADI, N. V. Frequency-and time-domain analysis of a novel UWB reconfigurable microstrip slot antenna with switchable notched bands. IET Microwaves, Antennas \& Propagation, 2017, vol. 11, no. 8, p. 1127-1132. DOI: 10.1049/iet-map.2016.0009

[30] KINGSLY, S., THANGARASU, D., KANAGASABAI, M., et al. Tunable band-notched high selective UWB filtering monopole antenna. IEEE Transactions on Antennas and Propagation, 2019, vol. 67 , no. 8 , p. 5658-5661. DOI: 10.1109/TAP.2019.2920997

\section{About the Authors...}

Houda AYADI was born in Ghardimaou, Tunisia. She received the master's degree in Electrical Engineering from 
the Faculty of Sciences of Tunis, Tunisia in 2014. She is currently working towards the Ph.D. degree in Electrical Engineering at the same faculty. Her main research interests lie in the reconfigurable and metamaterials antennas design.

Jan MACHAC was born in Hranice, Czechoslovakia, in 1953. He graduated from the CTU in Prague in 1977. He received his CSc. (Ph.D. equivalent) in Electronics in 1982 at the Institution of Radio Engineering and Electronics of the Czechoslovak Academy of Science in Prague. He received his Dr.Sc. degree in Radio Electronics in 1996 and was named a Professor of Electrical Engineering in 2009. His main scientific interests cover investigation of planar passive elements and subsystems of microwave technology, and propagation of electromagnetic waves in periodic structures and metamaterials. $\mathrm{He}$ is the author or co-author of more than 250 publications in scientific journals, including international ones as well as national conferences.

Sabri BELDI was born in Bousselem, Tunisia. He received the master's degree in Electrical Engineering from the Faculty of Sciences of Tunis, Tunisia. He received his
Ph.D. in Electronics in 2016 from the Faculty of Sciences of Tunis, Tunisia. He was named an Assistant Professor of Electrical Engineering in 2016. His main scientific interests cover investigation of planar passive elements and subsystems of microwave technology, propagation of electromagnetic waves in periodic structures and metamaterials. $\mathrm{He}$ is the author or coauthor of more than 25 publications in scientific journals, including international ones as well as national conferences.

Lassaad LATRACH was born in Tunis, Tunisia, on October 16, 1977. He received the BSEE and MS degrees in Electrical Engineering from the University of Tunis ElManar, in 2004 and 2006, respectively, and the Ph.D. degree in Electronics Systems High Frequency from the Faculty of Science, Tunis ElManar University, Tunisia, in 2010. Between 2010 and 2016, he was an Assistant Professor with the National School of Computer Sciences, University of Manouba, Tunisia. From 2016 to date, he is an Associate Professor in the same department. His current research interests are in design and modeling of high frequency circuits for communications applications. 